\title{
Use of Neutrosophic Logic in Defining River Water Quality of Yamuna
}

\author{
Dr Srijit Biswas, FIE $^{1}$, Sonal Bhugra ${ }^{2}$ \\ ${ }^{1}$ Professor, Deptt. of Civil Engineering, Manav Rachna International University, Faridabad, India \\ ${ }^{2}$ Assistant Professor, Deptt. of Civil Engineering, Manav Rachna International University, \\ Faridabad, India
}

\begin{abstract}
In this study we present a methodology of neutrosophic logic in defining river water quality of Yamuna, one of the most important river of Delhi. The laboratory test results of water quality parameters are not always found to be same in all locations of the river rather varies with wide range of interval daily, monthly and seasonally. For an engineer it is very difficult to define the water quality with degree of certainty. Thus it is quite normal for an expert to hesitate in his decision and feel more comfortable to express their views in the form of linguistic \& hedges viz. 'good', 'very good', 'low pH', 'less turbidity', 'high BOD', etc. to list a few only out of infinity. Such types of imprecise data are fuzzy in nature and uncertainty is an integral part of evaluation of each data. As a result the experts perceptions are not found 100\% truth rather a combination of truth, indeterminacy and falsity. To minimize the uncertainty from the perception result of expert we present a methodology of neutrosophic logic in present case study and define the river water quality of Yamuna more precisely.
\end{abstract}

Keywords: indeterminacy, membership function, neutrosophic logic, score function, weighted average, etc.

\section{INTRODUCTION}

River Yamuna which originates from Yamunotri glaciers in the lower Himalayas at an elevation of approximately 6387 meters is now become a most polluted rivers in India. Majority of the industries are set up on its bank since last 50-60 years and regularly dumping the untreated effluents into its body. Due to sedimentation of inorganic material into its bed the water flow changes significantly from monsoon to non-monsoon seasons and water found stagnant for approximately nine months in a year. As a result the loading of biochemical oxygen demand (BOD), chemical oxygen demand (COD) has increased dramatically that ultimately deteriorates the quality of fresh water and its quantity also. At present it becomes a great challenges to Govt of Delhi, capital of India to protect the Yamuna river from its anticipated all kinds of environmental degradation. All the activities which take place continuously in the river basin of Yamuna could adversely affect the environmental conditions of water quality and quantity, biological communities and the integrity of aquatic ecosystems. The laboratory test results of water quality in different locations of the river are not found same rather makes an interval data for each parameter. Naturally it is very difficult for an expert to define the quality of water with degree of certainty because of the involvement of uncertainty in his decision while taking based on such interval data. This study has solved this problem more precisely using generalized 'Neutrosophic' logic of Prof. Florentin Smarandache [5-6]. Generally this type of real life problems are tackled by the 'Intuitionistic' logic of Prof. K.T.Atanassov [1] where the summation of membership value, nonmembership value and hesitation always consider as one within sub set[0,1]. An intuitionistic fuzzy set is expressed as $A=\left\{\left(x: t_{A}(x), f_{A}(x)\right) \mid x \in E\right\}$ where the functions, $t_{A}(x): E \rightarrow[0,1]$ and $f_{A}(x)$ : $\mathrm{E} \rightarrow[0,1]$ define the degree of membership and the degree of non-membership of the element $\mathrm{x} \in \mathrm{E}$, respectively, and for every $x \in E$ there is a condition that $0 \leq t_{A}(x)+f_{A}(x) \leq 1$. The main novelty of Atanassov's approach is that $\left[\mathrm{t}_{\mathrm{A}}(\mathrm{x})+\mathrm{f}_{\mathrm{A}}(\mathrm{x})+\mathrm{i}_{\mathrm{A}}(\mathrm{x})\right]=1$, where the value of hesitation or indeterministic part of an IFS can estimate by $\mathrm{i}_{\mathrm{A}}(\mathrm{x})=\left[1-\mathrm{t}_{\mathrm{A}}(\mathrm{x})-\mathrm{f}_{\mathrm{A}}(\mathrm{x})\right]$. But in the present case study we use the neutrosophic logic of Florentin Smarandache where we do not even assume that 'incompleteness' or 'indeterminacy degree' is always given by $\left[1-t_{A}(x)-f_{A}(x)\right]$. Instead of that it estimate the percentage of truth in a subset $T$ where $t_{A}(x): X \rightarrow[0,1]$, percentage of indeterminacy in a subset $I$, where $i_{A}(x): X \rightarrow[0,1]$, percentage of falsity in a subset $F$, where $f_{A}(x) \rightarrow[0,1]$. In the neutrosophic logic the T, I, F are defined as standard or non-standard subsets of the non-standard 
interval $]^{-0}, 1^{+}\left[\right.$instead of $[0,1]$. Thus there is no restriction on the summation of $t_{A}(x), i_{A}(x)$ and $f_{A}(x)$, a condition exist in such that $\left[0 \leq \sup t_{A}(x) \leq \sup i_{A}(x) \leq \sup f_{A}(x) \leq 3\right]$. As this logic is more powerful than Atanassov's logic or any other higher order logic available in the present research field to tackle such kind of uncertainty, we use "Neutrosophic Logic" in this case study.

\section{Preliminaries}

In this section we present some preliminaries which will be useful to our main work in the next section.

\subsection{Fuzzy Set (Fs)}

Fuzzy set (FS) theory is the generalized form of normal crisp set theory first introduced by Prof. Latfi Zadeh in 1965 [8]. A crisp set is defined as a collection of objects or elements in a given domain in which object either belongs to the set or does not belong to the set. So in crisp set, our fillings, opinions, decisions, assessment, results etc can express only by one way either yes or no, true or false, white or black, day or night, accepted or not accepted, etc. It clearly indicate whether an element is a member of a given set or not and accordingly the membership value of any element should either be 0 or 1 . Neither in between of 0 or 1 . In below, suppose $X$ is an universal set and $A$ is a sub set of it and $\mathrm{x}, \mathrm{y}, \mathrm{z}$ are the elements of set $\mathrm{X}$ then in question of

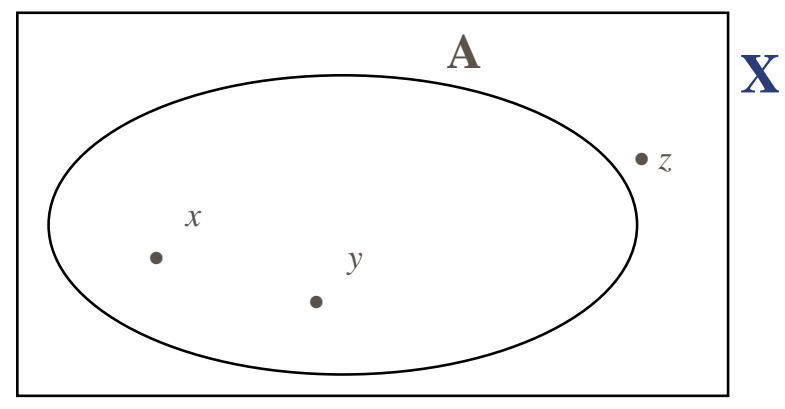

belongingness to it's subset $\mathrm{A}$, the membership value of element $\mathrm{x}$ and $\mathrm{y}$ is 1 but for $\mathrm{z}$ it is 0 . There is a clear boundary in between set $\mathrm{X}$ and it's sub set $\mathrm{A}$, in question of that which elements are actually belonging to the subset $\mathrm{A}$ and which are not belonging to sub set $\mathrm{A}$ [3-4].

But in fuzzy set (FS), there is no clear boundary in between set X and it's sub set A like crisp set, rather it is found vague \& doubt. According to fuzzy logic, when a statement is completely true, the membership value is 1 and when a statement is completely false the membership value is 0 and when the statement is partly true or partly false then the membership value will be in between 0 and 1 . Thus the membership function of a fuzzy set can take any independent value from the closed interval $[0,1]$ which to be assigned from the perception of decision makers or experts. It is defined as the set of ordered pairs, $A=\left\{\left(x_{1}, t_{A}\left(x_{1}\right)\right),\left(x_{2}, t_{A}\left(x_{2}\right)\right), \ldots\left(x_{n}, t_{A}\left(x_{n}\right)\right)\right\}$, where $t_{A}\left(x_{i}\right)$, is the grade of membership value of element $x_{i}$ in set $A$. The greater value of $t_{A}\left(x_{i}\right)$, indicates greater the truthness of statement that element $\mathrm{x}_{\mathrm{i}}$ belongs to set $\mathrm{A}[8]$.

\subsection{Intuitionistic Fuzzy Set (IFS)}

An intuitionistic fuzzy set (IFS) $\mathrm{B}$ in a universe of discourse $\mathrm{X}$ is defined as an object of the following form : $\mathrm{B}=\left\{\left(\mathrm{x}, \mathrm{t}_{\mathrm{B}}(\mathrm{x}), \mathrm{f}_{\mathrm{B}}(\mathrm{x})\right) \mid \mathrm{x} \in \mathrm{X}\right\}$

Where the functions, $t_{B}: X \rightarrow[0,1]$, and

$$
f_{B}: X \rightarrow[0,1]
$$

Define the degree of membership and degree of non-membership respectively of the element $\mathrm{x}$ with respect to the object $\mathrm{B}$. And for every $\mathrm{x} \in \mathrm{X}$ we have the relation

$0 \leq \mathrm{t}_{\mathrm{B}}(\mathrm{x})+\mathrm{f}_{\mathrm{B}}(\mathrm{x}) \leq 1$.

The amount $\pi_{B}(x)=1-\left(t_{B}(x)+f_{B}(x)\right)$ is called the hesitation part or in deterministic part of the element $\mathrm{x}$, and clearly, in case of ordinary fuzzy sets (Zadeh's fuzzy sets) it is presumed that there is no hesitation part for every element $\mathrm{x}$, i.e. $\pi_{\mathrm{B}}(\mathrm{x})=0$ for every $\mathrm{x} \in \mathrm{X}$. This logic has been introduced by Prof. K.T Atanasov in 1986 and presumed as a higher order fuzzy logic as compared to Zadeh's fuzzy logic[1,4]. 


\subsection{Neutrosophic Fuzzy Set (Nfs)}

Neutrosophic Fuzzy Set (NFS) is a general framework for unification of many existing logics, such as fuzzy logic, intuitionistic fuzzy logic, paraconsistent logic, etc. introduced by Prof. Florentin Smarandache in 1999. The main idea of NFS is to characterize each logical statement in a 3D neutrosophic space, where each dimension of the space represents respectively the truth $(\mathrm{T})$, the falsehood (F), and the determinacy (I) of the statement under consideration, where T, I, F are standard or non-standard real subsets within $]^{-0}, 1^{+}[$and not necessarily any connection between them. Thus a neutrosophic set $\mathrm{C}$ in $\mathrm{X}$ can be defined by a truth membership function $\mathrm{T}_{\mathrm{C}}(\mathrm{x})$, an indeterminacy function $\mathrm{I}_{\mathrm{C}}(\mathrm{x})$ and a falsity membership function $\mathrm{F}_{\mathrm{C}}(\mathrm{x}) . \mathrm{T}_{\mathrm{C}}(\mathrm{x}), \mathrm{I}_{\mathrm{C}}(\mathrm{x})$ and $\mathrm{F}_{\mathrm{C}}(\mathrm{x})$ are real standard or real non-standard sub sets of] $0,1^{+}$[ where $1^{+}=1+\varepsilon$ and $0=0-\varepsilon$. Here " 1 " and " 0 " are the standard part and " $\varepsilon$ " its non-standard part [5-7]. That is $\left.\mathrm{T}_{\mathrm{C}}(\mathrm{x}): \mathrm{x} \rightarrow\right]^{-} 0,1^{+}\left[, \mathrm{I}_{\mathrm{C}}(\mathrm{x}): \mathrm{x} \rightarrow\right]^{-0} 0,1^{+}\left[\right.$and $\mathrm{F}_{\mathrm{C}}(\mathrm{x}): \mathrm{x}$ $\rightarrow]^{-} 0,1^{+}\left[\right.$. There is no restriction on the sum of $T_{C}(x), I_{C}(x)$ and $F_{C}(x)$ so $0 \leq t_{A}(x)+i_{C(x)}+f_{C(x)} \leq 3^{+}$ [5-6]. In general refined neutrosophic logic, $T$ can be split into subcomponents $T_{1}, T_{2}, T_{3}, \ldots . . T p$ and I into $I_{1}, I_{2}, I_{3}, \ldots$, Ir and $F$ into $F_{1}, F_{2}, F_{3}, \ldots$, Fs where $t_{C}(x): X \rightarrow[0,1], \quad i_{C}(x): X \rightarrow[0,1]$ and $\mathrm{f}_{\mathrm{C}}(\mathrm{x}): \mathrm{X} \rightarrow[0,1]$ with $0 \leq \mathrm{t}_{\mathrm{C}}(\mathrm{x})+\mathrm{i}_{\mathrm{C}(\mathrm{x})}+\mathrm{f}_{\mathrm{C}(\mathrm{x})} \leq 3$ for all $\mathrm{x} \in \mathrm{X}$. The $\mathrm{t}_{\mathrm{C}}(\mathrm{x}), \mathrm{i}_{\mathrm{C}}(\mathrm{x})$ and $\mathrm{f}_{\mathrm{C}}(\mathrm{x})$ denote the truth-membership degree, the indeterminacy-membership degree and the falsity membership degree of $\mathrm{x}$ to the universal set $\mathrm{X}[2,7]$.

\subsection{Single Valued Neutrosophic Sets (SVNS) [7]}

If $A$ is the single valued neutrosophic set of the universe $X$ and $t_{A}(x), i_{A}(x)$ and $f_{A}(x)$ denote the truthmembership degree, the indeterminacy-membership degree and the falsity membership degree of $x$ to the universal set $\mathrm{X}$ then

$$
\begin{aligned}
& \left.A=\left\{\left(x: t_{A}(x), i_{A}(x), f_{A}(x)\right)\right) \mid x \in E\right\} \\
& \text { where } t_{A}(x): X \rightarrow[0,1], i_{A}(x): X \rightarrow[0,1] \text { and } f_{A}(x): X \rightarrow[0,1] \\
& \text { With } 0 \leq t_{A}(x)+i_{A(x)}+f_{A(x)} \leq 3 \text { for all } x \in X
\end{aligned}
$$

\section{Methodology}

The proposed methodology deals with the model of 'Neutrosophic Logic (NL)' and assesses the quality of Yamuna river water more precisely. This model helps to remove all the drawbacks commonly found when assess by the Intuitionistic Fuzzy logic of Prof. K.T. Atanossov. This case study is conducted in two phases: in phase-I, water samples are collected from different locations of the river across the stretch of Delhi and thereafter conducted laboratory test for all samples. In phaseII, expert's views and perceptions are collected for evaluation of every water parameter of the laboratory test results individually from different experts. Selection of experts and collection of their views and perceptions are thus the integral part of this methodology. Now some useful definitions are presented below which will help to understand the present methodology in better way:-

\subsection{Fuzzy Alternatives Statement (Fas)}

For evaluation of river water quality based on the laboratory test results of different locations, expert's perception are obtained on interviewing or questionnaires method and the outcome results are always found in linguistic variable like 'high turbidity', 'high pH', 'very high BOD', 'low TDS', etc. All these data are obviously called fuzzy data but in NL, these are called as fuzzy alternatives statements (FAS).

\subsection{Score Function of SVNS}

If $A=\left[t_{A}(x), i_{A}(x), f_{A}(x)\right]$ be a single valued neutrosophic number (SVN), a score function $S$ of a single valued neutrosophic value, based on the truth-membership degree, indeterminacy-membership dégrée and false membership degree, then the score function is defined by the crisp number as

$$
S(A)=\frac{1+t_{A}(x)-2 i_{A}(x)-f_{A}(x)}{2}
$$

Where, $S(A) \in[-1,1]$ and $t_{A}(x)+i_{A(x)}+f_{A(x)} \leq 3$ for all $x \in X$

Example : Let $\mathrm{A}_{1}=(0.5,0.2,0.4)$ and $\mathrm{A}_{2}=((0.4,0.1,0.3)$ be two single valued neutrosophic numbers for two alternatives. Then the 


$$
\begin{aligned}
& S\left(A_{1}\right)=\frac{1+0.5-2 \times 0.2-0.4}{2}=0.35 \\
& S\left(A_{2}\right)=\frac{1+0.4-2 \times 0.1-0.3}{2}=0.45
\end{aligned}
$$

Naturally we can say that alternative décision of $A_{2}$ is better than $A_{1}$.

\subsection{Universe of Fuzzy Alternatives Statement (UFAS)}

Collection of all fuzzy alternatives statements is called the Universe of Fuzzy Alternatives Statement (UFAS).

\subsection{Mean Fuzzy Set of a NS}

Let $X$ be an universe of fuzzy alternatives statement (UFAS) and A be a NS of X. The mean fuzzy set of the NS A is also a fuzzy set $\mathrm{M}$ of $\mathrm{X}$ given by the membership function

$$
\mu_{\mathrm{m}}\left(\mathrm{x}_{\mathrm{i}}\right)=\frac{\sum \mathrm{S}\left(\mathrm{A}_{\mathrm{i}}\right)}{\mathrm{N}}
$$

Where, $\mathrm{N}=$ total number of locations and $\sum \mathrm{S}\left(\mathrm{A}_{\mathrm{i}}\right)=$ sum of score function of SVNS $(\mathrm{S})$ of set $\mathrm{A}_{\mathrm{i}}$ for all locations of river under consideration.

\subsection{Weighted Average of Neutrosophic Set (NS)}

Let $\mu_{\mathrm{m}}\left(\mathrm{x}_{\mathrm{i}}\right)$ be a mean fuzzy set of a finite neutrosophic set $\mathrm{X}$. Suppose that to each element $\mathrm{x} \in \mathrm{X}$, there is an associated weight $\mathrm{w}_{\mathrm{i}} \in R+$ (which could be prefixed by the common decision of all water quality experts or by the water management authorities before commencement of case study), then the 'weighted average' of the mean neutrosophic set $\mu_{\mathrm{m}}\left(\mathrm{x}_{\mathrm{i}}\right)$ is the non-negative number $\mathrm{a}(\mu)$ is given by

$$
\mathrm{a}(\mu)=\frac{\sum \mu_{\mathrm{m}}\left(\mathrm{x}_{\mathrm{i}}\right) \cdot \mathrm{w}_{\mathrm{i}}}{\sum \mathrm{w}_{\mathrm{i}}} \forall, \quad \mathrm{i}=1,2,3, \ldots \ldots .
$$

\subsection{Grading of Fuzzy Assessment Output}

In NS modeling, evaluations of all FAS are done either based on their negative aspects (draw backs) or positive aspects. If negative aspects of all attributes are consider then grading of output results of NS could be proposed as below:

$\begin{array}{llll}\text { For "Worst", } & \text { grade }=\mathbf{A}, \quad \text { if } & .8<\mathrm{a}(\mu) \leq 1 \\ \text { For "Bad", } & \text { grade }=\mathbf{B}, \quad \text { if } & .6<\mathrm{a}(\mu) \leq .8 \\ \text { For "Moderate", } & \text { grade }=\mathbf{C}, \text { if } & .4<\mathrm{a}(\mu) \leq .6 \\ \text { For "Good", } & \text { grade }=\mathbf{D}, \quad \text { if } & .2<\mathrm{a}(\mu) \leq .4 \\ \text { For "Best", } & \text { grade }=\mathbf{E}, \quad \text { if } & 0 \leq \mathrm{a}(\mu) \leq .2 .\end{array}$

Similarly for positive aspects, grading of output result of NS could be proposed as:

$\begin{array}{lll}\text { For "Best", } & \text { grade } & =\mathbf{A}, \text { if } .8<\mathrm{a}(\mu) \leq 1 \\ \text { For "Good", } & \text { grade } & =\mathbf{B}, \text { if } \quad .6<\mathrm{a}(\mu) \leq .8 \\ \text { For "Moderate", } & \text { grade } & \mathbf{C}, \text { if } \quad .4<\mathrm{a}(\mu) \leq .6 \\ \text { For "Bad", } & \text { grade }=\mathbf{D}, \text { if } \quad .2<\mathrm{a}(\mu) \leq .4 \\ \text { For "Worst", } & \text { grade }=\mathbf{E}, \text { if } \quad 0 \leq \mathrm{a}(\mu) \leq .2 .\end{array}$


In next section we present a case study using NS methodology for assessment of river water quality with more degree of certainty. We select the river Yamuna which is a most important river of Delhi, capital of India but due to poor planning and management the river is now struggling for its future survive.

\section{Case Study}

In the present case study, ten water parameters and seven locations of river Yamuna has been selected for assessment. Monthly one water sample from each location is collected from January'2015 to November'2015 and laboratory test results of all the samples are obtained. For a particular parameter of a particular location, all laboratory test results are not found precise or pointed data rather varied with wide range of interval data. All these interval data are tabulated below in Table-1 and considered as base line data of "NS-methodology". For evaluation of these data, ten water quality experts has also been selected to obtain their views and perception towards quality of water of River Yamuna and assess the truth-membership degree, the indeterminacy-membership degree and the falsity membership degree of each evaluation activity.

(Table-1)

\begin{tabular}{|c|c|c|c|c|c|c|c|}
\hline Parameter & $\begin{array}{l}\text { Palla } \\
\left(\mathrm{L}_{1}\right)\end{array}$ & $\begin{array}{l}\text { Old Delhi } \\
\text { Railway } \\
\text { Bridge }\left(\mathrm{L}_{2}\right)\end{array}$ & $\begin{array}{l}\text { Nizamu-ddin } \\
\left(\mathrm{L}_{3}\right)\end{array}$ & Rajghat $\left(\mathrm{L}_{4}\right)$ & $\begin{array}{l}\text { ISBT } \\
\left(\mathrm{L}_{5}\right)\end{array}$ & $\begin{array}{l}\text { Sarai Kale } \\
\text { Khan }\left(\mathrm{L}_{6}\right)\end{array}$ & Okhla $\left(\mathrm{L}_{7}\right)$ \\
\hline $\mathrm{P}_{\mathrm{H}}$ & $\begin{array}{ll}6.78 & - \\
9.18 & \end{array}$ & $6.78-8.93$ & $6.98-8.86$ & $6.81-8.89$ & $6.82-8.88$ & $6.62-8.76$ & $6.83-8.91$ \\
\hline $\begin{array}{l}\text { Turbidity } \\
\text { (NTU) }\end{array}$ & $\begin{array}{l}5.55- \\
9.98\end{array}$ & $\begin{array}{l}15.56- \\
18.36\end{array}$ & $6.64-11.25$ & $6.38-10.56$ & $15.67-24.43$ & $\begin{array}{l}51.25- \\
170.56\end{array}$ & $\begin{array}{l}205.21- \\
307.26\end{array}$ \\
\hline $\begin{array}{l}\text { Alkalinity } \\
(\mathrm{mg} / \mathrm{l})\end{array}$ & $170-280$ & $176-275$ & $160-290$ & $185-305$ & $175-310$ & $180-305$ & $250-315$ \\
\hline $\begin{array}{l}\text { Hardness } \\
\text { as }\left(\mathrm{CaCO}_{3}\right)\end{array}$ & $150-200$ & $325-405$ & $403-500$ & $405-450$ & $190-300$ & $390-500$ & $402-600$ \\
\hline $\begin{array}{l}\text { Ammonia } \\
(\mathrm{mg} / \mathrm{l})\end{array}$ & $\begin{array}{l}0.01- \\
3.96\end{array}$ & $0.03-39.98$ & $0.01-42$ & $0.05-7.23$ & $0.08-8.91$ & $0.09-6.76$ & $1.34-7.23$ \\
\hline TDS (mg/l) & $\begin{array}{l}80.12- \\
150.55\end{array}$ & $400-600$ & $1130-1450$ & $100-205$ & $200-280$ & $1250-1680$ & $1390-1950$ \\
\hline DO (mg/l) & $3-16.8$ & $0.01-5.87$ & $0.01-5.53$ & $0.01-5.98$ & $0.02-5.88$ & $0.01-6.20$ & $0.01-6.10$ \\
\hline $\mathrm{COD}(\mathrm{mg} / \mathrm{l})$ & 4-34 & $21-70$ & $26-106$ & $35-103$ & $50-168$ & $87-210$ & $65-194$ \\
\hline $\mathrm{BOD}_{5}(\mathrm{mg} / \mathrm{l})$ & $1-8$ & $4.2-78$ & $3.3-62$ & $3.0-63$ & $2.98-69$ & $3.6-67$ & $2.9-64$ \\
\hline $\begin{array}{l}\text { Total } \\
\text { Coliform } \\
(\mathrm{MPN} / 100 \mathrm{ml})\end{array}$ & $\begin{array}{l}210 \quad- \\
205165\end{array}$ & $\begin{array}{l}4803- \\
90029705\end{array}$ & $\begin{array}{l}78000- \\
980000000\end{array}$ & $\begin{array}{l}87000- \\
146000000\end{array}$ & $\begin{array}{l}79000- \\
154000000\end{array}$ & $\begin{array}{l}88000- \\
168000000\end{array}$ & $\begin{array}{l}91000- \\
138000000\end{array}$ \\
\hline
\end{tabular}

Now the job is to construct fuzzy alternatives statements (FAS) considering negative aspects (draw backs) for the above ten parameters and assign the score function of $\operatorname{SVNS~}_{\mathrm{L}}\left(\mathrm{x}_{\mathrm{i}}\right)$ :-

$$
\begin{aligned}
& \mathrm{x}_{1}=\text { high } \mathrm{pH} \\
& \mathrm{x}_{2}=\text { high turbidity } \\
& \mathrm{x}_{3}=\text { high alkalinity } \\
& \mathrm{x}_{4}=\text { high hardness as }\left(\mathrm{CaCO}_{3}\right) \\
& \mathrm{x}_{5}=\text { high ammonia } \\
& \mathrm{x}_{6}=\text { high TDS (total dissolved solids) } \\
& \mathrm{x}_{7}=\text { less DO } \\
& \mathrm{x}_{8}=\text { high COD } \\
& \mathrm{x}_{9}=\text { high BOD } \\
& \mathrm{x}_{10}=\text { high total coliform (MPN/100ml) }
\end{aligned}
$$

Suppose $A$ is the single valued neutrosophic set of universe $X$ where $t_{A}(x), i_{A}(x)$ and $f_{A}(x)$ denoted the truth-membership degree, the indeterminacy-membership degree and the falsity membership degree of $x$ to the Universe of Fuzzy Alternatives Statement (UFAS) X then for individual location, the individual $\mathrm{SVN}$ sets $\mathrm{A}_{\mathrm{L}}$ could be written as below :- 


$$
\begin{aligned}
& \mathrm{A}_{\mathrm{L} 1}=\left\{\left(\mathrm{x}_{1}, 0.2,0.3,0.5\right),\left(\mathrm{x}_{2}, 0.5,0.3,0.2\right),\left(\mathrm{x}_{3}, 0.5,0.6,0.2\right),\left(\mathrm{x}_{4}, 0.8,0.1,0.2\right),\left(\mathrm{x}_{5}, 0.7,0.1,0.2\right),\right. \\
& \left(\mathrm{x}_{6}, 0.6,0.2,0.4\right),\left(\mathrm{x}_{7}, 0.5,0.5,0.1\right),\left(\mathrm{x}_{8}, 0.6,0.4,0.2\right),\left(\mathrm{x}_{9}, 0.7,0.6,0.1\right) .\left(\mathrm{x}_{10}, 0.8,0.2,0.1\right) . \\
& \mathrm{A}_{\mathrm{L} 2}=\left\{\left(\mathrm{x}_{1}, 0.5,0.6,0.2\right),\left(\mathrm{x}_{2}, 0.2,0.7,0.4\right),\left(\mathrm{x}_{3}, 0.2,0.6,0.2\right),\left(\mathrm{x}_{4}, 0.5,0.3,0.4\right),\left(\mathrm{x}_{5}, 0.4,0.6,0.2\right),\right. \\
& \left(\mathrm{x}_{6}, 0.8,0.1,0.1\right),\left(\mathrm{x}_{7}, 0.4,0.2,0.6\right),\left(\mathrm{x}_{8}, 0.5,0.4,0.2\right),\left(\mathrm{x}_{9}, 0.7,0.3,0.3\right),\left(\mathrm{x}_{10}, 0.7,0.6,0.1\right) . \\
& \mathrm{A}_{\mathrm{L} 3}=\left\{\left(\mathrm{x}_{1}, 0.5,0.2,0.4\right),\left(\mathrm{x}_{2}, 0.7,0.3,0.2\right),\left(\mathrm{x}_{3}, 0.5,0.6,0.2\right),\left(\mathrm{x}_{4}, 0.5,0.5,0.3\right),\left(\mathrm{x}_{5}, 0.5,0.2,0.3\right),\right. \\
& \left(\mathrm{x}_{6}, 0.6,0.2,0.1\right),\left(\mathrm{x}_{7}, 0.5,0.3,0.2\right),\left(\mathrm{x}_{8}, 0.8,0.1,0.1\right),\left(\mathrm{x}_{9}, 0.5,0.4,0.3\right) .\left(\mathrm{x}_{10}, 0.6,0.4,0.2\right) . \\
& \mathrm{A}_{\mathrm{L} 4}=\left\{\left(\mathrm{x}_{1}, 0.4,0.3,0.7\right),\left(\mathrm{x}_{2}, 0.5,0.1,0.6\right),\left(\mathrm{x}_{3}, 0.5,0.6,0.1\right),\left(\mathrm{x}_{4}, 0.7,0.6,0.2\right),\left(\mathrm{x}_{5}, 0.5,0.6,0.2\right),\right. \\
& \left(\mathrm{x}_{6}, 0.6,0.5,0.2\right),\left(\mathrm{x}_{7}, 0.2,0.2,0.7\right),\left(\mathrm{x}_{8}, 0.3,0.5,0.6\right),\left(\mathrm{x}_{9}, 0.5,0.3,0.2\right) .\left(\mathrm{x}_{10}, 0.7,0.5,0.1\right) . \\
& \mathrm{A}_{\mathrm{L} 5}=\left\{\left(\mathrm{x}_{1}, 0.3,0.4,0.6\right),\left(\mathrm{x}_{2}, 0.4,0.5,0.2\right),\left(\mathrm{x}_{3}, 0.8,0.2,0.2\right),\left(\mathrm{x}_{4}, 0.5,0.6,0.2\right),\left(\mathrm{x}_{5}, 0.8,0.2,0.3\right)\right. \text {, } \\
& \left(\mathrm{x}_{6}, 0.5,0.3,0.3\right),\left(\mathrm{x}_{7}, 0.6,0.3,0.2\right),\left(\mathrm{x}_{8}, 0.7,0.4,0.2\right),\left(\mathrm{x}_{9}, 0.6,0.4,0.1\right) .\left(\mathrm{x}_{10}, 0.5,0.3,0.3\right) . \\
& \mathrm{A}_{\mathrm{L} 6}=\left\{\left(\mathrm{x}_{1}, 0.5,0.3,0.2\right),\left(\mathrm{x}_{2}, 0.6,0.2,0.2\right),\left(\mathrm{x}_{3}, 0.7,0.2,0.2\right),\left(\mathrm{x}_{4}, 0.6,0.2,0.5\right),\left(\mathrm{x}_{5}, 0.5,0.6,0.2\right),\right. \\
& \left(\mathrm{x}_{6}, 0.8,0.2,0.4\right),\left(\mathrm{x}_{7}, 0.7,0.1,0.6\right),\left(\mathrm{x}_{8}, 0.5,0.3,0.3\right),\left(\mathrm{x}_{9}, 0.9,0.1,0.2\right) .\left(\mathrm{x}_{10}, 0.7,0.3,0.1\right) . \\
& \mathrm{A}_{\mathrm{L} 7}=\left\{\left(\mathrm{x}_{1}, 0.2,0.6,0.4\right),\left(\mathrm{x}_{2}, 0.6,0.2,0.2\right),\left(\mathrm{x}_{3}, 0.3,0.6,0.2\right),\left(\mathrm{x}_{4}, 0.2,0.2,0.7\right),\left(\mathrm{x}_{5}, 0.6,0.4,0.2\right)\right. \text {, } \\
& \left(\mathrm{x}_{6}, 0.5,0.4,0.2\right),\left(\mathrm{x}_{7}, 0.4,0.6,0.3\right),\left(\mathrm{x}_{8}, 0.5,0.3,0.2\right),\left(\mathrm{x}_{9}, 0.3,0.6,0.2\right) .\left(\mathrm{x}_{10}, 0.8,0.3,0.1\right) .
\end{aligned}
$$

These data leads to the neutrosophic fuzzy set (NFS) A of the Universe of Fuzzy Alternatives Statement (UFAS) X,

where, $X=\left\{x_{1}, x_{2}, x_{3}, x_{4}, x_{5}, x_{6}, x_{7}, x_{8}, x_{9}, x_{10}\right\}$.

The Score Function fuzzy set $S_{L}$ of the above SVNS

$S_{\mathrm{L} 1}=\left\{\left(\mathrm{x}_{1}, .05\right),\left(\mathrm{x}_{2}, .35\right),\left(\mathrm{x}_{3}, .05\right),\left(\mathrm{x}_{4}, .70\right),\left(\mathrm{x}_{5},-0.65\right),\left(\mathrm{x}_{6}, .40\right),\left(\mathrm{x}_{7}, .20\right),\left(\mathrm{x}_{8}, .30\right),\left(\mathrm{x}_{9}, .20\right),\left(\mathrm{x}_{10}, .65\right)\right.$

$\mathrm{S}_{\mathrm{L} 2}=\left\{\left(\mathrm{x}_{1}, .05\right),\left(\mathrm{x}_{2},-0.30\right),\left(\mathrm{x}_{3},-0.10\right),\left(\mathrm{x}_{4}, .25\right),\left(\mathrm{x}_{5}, 0\right),\left(\mathrm{x}_{6}, .75\right),\left(\mathrm{x}_{7}, .20\right),\left(\mathrm{x}_{8}, 25\right),\left(\mathrm{x}_{9}, .40\right),\left(\mathrm{x}_{10}, 0.20\right)\right.$

$\mathrm{S}_{\mathrm{L} 3}=\left\{\left(\mathrm{x}_{1}, .35\right),\left(\mathrm{x}_{2}, .45\right),\left(\mathrm{x}_{3}, .05\right),\left(\mathrm{x}_{4}, .10\right),\left(\mathrm{x}_{5}, .40\right),\left(\mathrm{x}_{6}, .55\right),\left(\mathrm{x}_{7}, .35\right),\left(\mathrm{x}_{8}, .75\right),\left(\mathrm{x}_{9}, . .20\right),\left(\mathrm{x}_{10}, .30\right)\right.$.

$\mathrm{S}_{\mathrm{L} 4}=\left\{\left(\mathrm{x}_{1}, .05\right),\left(\mathrm{x}_{2}, .35\right),\left(\mathrm{x}_{3}, .10\right),\left(\mathrm{x}_{4}, .15\right),\left(\mathrm{x}_{5}, .05\right),\left(\mathrm{x}_{6}, .20\right),\left(\mathrm{x}_{7}, .05\right),\left(\mathrm{x}_{8},-.15\right),\left(\mathrm{x}_{9}, .35\right),\left(\mathrm{x}_{10}, .30\right)\right.$.

$\mathrm{S}_{\mathrm{L} 5}=\left\{\left(\mathrm{x}_{1},-.05\right),\left(\mathrm{x}_{2}, .10\right),\left(\mathrm{x}_{3}, .60\right),\left(\mathrm{x}_{4}, .05\right),\left(\mathrm{x}_{5}, .55\right),\left(\mathrm{x}_{6}, .30\right),\left(\mathrm{x}_{7}, .40\right),\left(\mathrm{x}_{8}, .35\right),\left(\mathrm{x}_{9}, .35\right),\left(\mathrm{x}_{10}, .30\right)\right.$.

$\mathrm{S}_{\mathrm{L} 6}=\left\{\left(\mathrm{x}_{1}, .35\right),\left(\mathrm{x}_{2}, .50\right),\left(\mathrm{x}_{3}, .55\right),\left(\mathrm{x}_{4}, .35\right),\left(\mathrm{x}_{5}, .05\right),\left(\mathrm{x}_{6}, .50\right),\left(\mathrm{x}_{7}, .45\right),\left(\mathrm{x}_{8}, .30\right),\left(\mathrm{x}_{9}, .75\right),\left(\mathrm{x}_{10}, .50\right)\right.$.

$\mathrm{S}_{\mathrm{L} 7}=\left(\mathrm{x}_{1},-.20\right),\left(\mathrm{x}_{2}, .50\right),\left(\mathrm{x}_{3},-.05\right),\left(\mathrm{x}_{4}, .05\right),\left(\mathrm{x}_{5}, .30\right),\left(\mathrm{x}_{6}, .25\right),\left(\mathrm{x}_{7},-.05\right),\left(\mathrm{x}_{8}, .35\right),\left(\mathrm{x}_{9},-.05\right),\left(\mathrm{x}_{10}, .55\right)$.

These data also leads to the neutrosophic set (NS) $\mathrm{S}_{\mathrm{L}}$ of the Universe of Fuzzy Alternatives Statement (UFAS) X,

where, $X=\left\{x_{1}, x_{2}, x_{3}, x_{4}, x_{5}, x_{6}, x_{7}, x_{8}, x_{9}, x_{10}\right\}$.

Now the mean fuzzy set of the NS $\mathrm{S}_{\mathrm{L}}$ is assessed by :

$\mu_{\mathrm{m}}(\mathrm{x})_{\mathrm{SL}}=\left\{\left(\mathrm{x}_{1}, .09\right),\left(\mathrm{x}_{2}, .28\right),\left(\mathrm{x}_{3}, .17\right),\left(\mathrm{x}_{4}, 24\right),\left(\mathrm{x}_{5}, .10\right),\left(\mathrm{x}_{6}, .42\right),\left(\mathrm{x}_{7}, .23\right),\left(\mathrm{x}_{8}, .31\right),\left(\mathrm{x}_{9}, .31\right),\left(\mathrm{x}_{10}, .40\right)\right.$

Suppose weight of each attributes of set $\mathrm{X}$ are prefixed by the seven experts like as for $\mathrm{x}_{1}=10$, for $\mathrm{x}_{2}$ $=60$, for $\mathrm{x}_{3}=55$, for $\mathrm{x}_{4}=40$, for $\mathrm{x}_{5}=80$, for $\mathrm{x}_{6}=35$, for $\mathrm{x}_{7}=50$, for $\mathrm{x}_{8}=90$, for $\mathrm{x}_{9}=80$, and for $\mathrm{x}_{10}=$ 95 respectively. Now the mean fuzzy set of the Score Function fuzzy set $S_{L}$ and weighted average of neutrosophic set A is assessed in Table-2 which is " $\mathbf{0 . 4 9 "}$ and consequently the grade is awarded as "C'.

(Table-2)

\begin{tabular}{|c|c|c|c|}
\hline Attribute & $\begin{array}{c}\text { Mean fuzzy set of } \\
\text { Neutrosophic }\left[\mu_{\mathrm{m}}(\mathrm{x})_{\mathrm{SL}}\right]\end{array}$ & $\begin{array}{c}\text { weight of the attribute } \\
\left(\mathrm{W}_{\mathrm{x}}\right)\end{array}$ & $\begin{array}{c}\text { Weighted average of } \\
\text { Neutrosophic Set }[\mathrm{a}(\mu)]\end{array}$ \\
\hline $\mathrm{x}_{1}$ & .09 & 10 & \\
$\mathrm{x}_{2}$ & .28 & 60 & \\
$\mathrm{x}_{3}$ & .17 & 55 & $\mathbf{0 . 4 9}$ \\
$\mathrm{x}_{4}$ & .24 & 40 & \\
$\mathrm{x}_{5}$ & .10 & 80 & \\
$\mathrm{x}_{6}$ & .42 & 35 & \\
$\mathrm{x}_{7}$ & .23 & 50 & \\
$\mathrm{x}_{8}$ & .31 & 90 & \\
$\mathrm{x}_{9}$ & .31 & 80 & \\
$\mathrm{x}_{10}$ & .40 & 95 & \\
\hline
\end{tabular}




\section{CONCLUSION}

The outcome result of present case study reveals that water quality of river "Yamuna" is in the grade of 'MODERATE' as per environmental condition is concern. For evaluation of multiple data against a particular parameter, it is very difficult for an expert to judge it's degree of truthness. Because every time the expert's perception will influence him in a specific track of knowledge and their resultant will give him capability to express the outcome result of that parameter which involved lots of uncertainties. The tool "neutrosophic logic" is used in this case study to tackle the uncertainty involved in the perception of experts and it gives more precise result with degree of confidence. Using this tool any expert can feel more comfortable and satisfaction for evaluation of any multiple data as used in the present case study. The model will also help in ranking of different river water's quality and will serve an important information to the authority for future development project. Here we do not consider the local politics, local constraints, local public grievances etc. which may directly influence the decision maker and leads great errors in the final decision of the expert.

\section{REFERENCES}

[1] Atanassov.K.T. (1986); 'Instuitionistic Fuzzy Sets', Fuzzy Sets and System, vol-20, no-1, pp87-96.

[2] Biswas, Ranjit. Pandey. U.S. (2011); Neutrosophic Relational Database Decomposition, "International Journal of Advance Computer Science and Applications, vol-2, no-8, pp-121-125.

[3] Biswas, Srijit. (2005); 'A Fuzzy Approach to Environmental Impact Assessment', Asian Journal. of Information Technology, Grace Publication Network, vol-4 (1) , pp-35-39.

[4] Biswas, Srijit.(1998); 'Environmental Impact Assessment: An Intuitionistic Fuzzy Approach', Proceeding of the Second International Conference on IFS. Sofia,3-4Oct.1998, pp-23-27, (Published in the international journal NIFS, of Bulgaria).

[5] Smarandache, F. (1999); 'A unifying field in logics, Neutrosophy: Neutrosophic Probability, set and logic', American Research Press, Rehoboth.

[6] Smarandache, F.(2005); 'A generalization of the Instuitionistic Fuzzy Set', International Journal of Pure and Applied Mathematics, 24, pp-287-297.

[7] Wang. H.; Smarandache, F.; Zhang, Y. Q., and Sunderrman. R.(2010); Single valued neutrosophic sets, Multispace and Multistructure, vol-4, pp-410-413

[8] Zadeh. L.A.(1965); 'Fuzzy Sets: Information and Control', vol-8, no-3, pp-338-353.

\section{AuTHORS' BIOGRAPHY}

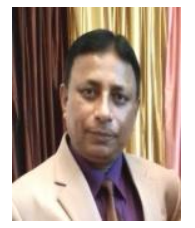

Dr. Srijit Biswas, He has obtained his Ph.D from Jadavpur University and M.E from Calcutta University, India. He is 'Fellow' of Institute of Engineers (India) and working as a Professor, Department of Civil Engineering, Manav Rachna International University, Faridabad. He has more than 28 years experiences. He is the member of editorial board of many reputed international journals and reviewers of many international and national journals. He authored a book on the area of 'Fuzzy EIA' published from Germany.

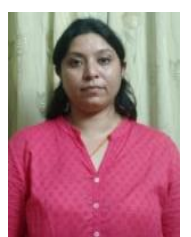

Ms. Sonal Bhugra, She has obtained M.Tech from Maharishi Dayanand University in Transportation Engineering and A.M.I.E in Civil Engg. from Institute of Engineers (India). Currently she is working as an Assistant Professor, Department of Civil Engineering, Manav Rachna International University, Faridabad. She has 7 years of teaching experience. 